\title{
Summary of perioperative calcium regulation therapy and analysis of related factors in the treatment of secondary hyperparathyroidism
}

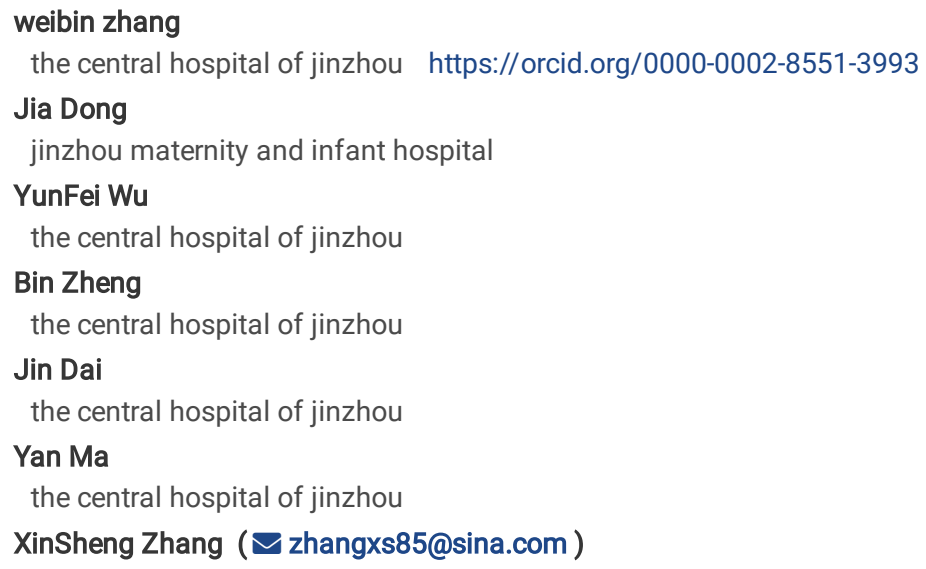




\section{Abstract}

Background $\otimes$ Retrospectively register the clinical data of secondary hyperparathyroidism $₫$ SHPT囚patients who received surgical treatment, summarize the postoperative calcium regulation scheme in details and analyze statistically related factors for guiding clinical early intervention and evaluating prognosis.

Methods: Review the clinical data of 136 patients with chronic renal failure in uremic stage from Jinzhou Central Hospital and the Second Affiliated Hospital of Dalian Medical University, who received dialysis treatment for a long time and finally diagnosed as secondary hyperparathyroidism, from Jan 2017 to Dec 2019, were accepted different operations to treat hyperparathyroidism, were given corresponding calcium regulation therapy to avoid serious complicationswere, and were divided into the observation group and the control group according to the postoperative calcium regulation time of $\leq 7$ days and $>7$ days, which is defined as the time from the day of operation until the day when the patients have stable blood calcium levels and no obvious discomfort symptoms.

Results: The difference between the two groups was statistically significant $(P<0.001)$; Compared with the control group, the observation group were elder(54.01 $\pm 9.215 ; \mathrm{P}<0.01)$, shorter preoperative dialysis time (5.05 $\pm 2.855 ; \mathrm{P}<0.01)$; significant difference in operation mode $(\mathrm{P}=0.026)$; positive preoperative oral calcium $\left(c^{2}=9.941, P=0.002\right)$, higher preoperative calcium value $(t=4.795 ; P<0.001)$, lower preoperative Parathyroid Hormone $(P T H)$ value $(t=6.327 ; P<0.001)$, lower preoperative Alkaline phosphatase(ALP) value $(t=3.527 ; P=0.001)$; Multivariate analysis showed that age, preoperative calcium value, preoperative PTH value and preoperative ALP value were independent risk factors for postoperative calcium regulation therapy. Those factors, Gender, preoperative dialysis mode, complications, preoperative Hemoglobin(HB) value, were not related to postoperative calcium regulation. There was no significant difference between the two groups $(P>0.05)$.

Conclusion: Effective postoperative calcium regulation can maintain a stable level of blood calcium in the patients with secondary hyperparathyroidism, so as to avoid the occurrence of severe hypocalcemia.

\section{Background}

Medicine treatment is ineffective to Secondary hyperparathyroidism and aggravates its clinical symptoms, such as bone pain, myalgia, skeletal deformity, atherosclerotic changes in the cardiovascular system and neuropathy, which is seriously affecting daily life of the patients or even threatening their life. Surgeries have been widely embraced as the important clinical treatment. Various modes of operations are offered, such as Subtotal parathyroidectomy (SPTX), Total parathyroidectomy(tPTX), Total Paratyroidectomy with autotransplatation (TPTX-AT). However, the incidence of severe hypocalcemia reaches $97 \%$ after these operations ${ }^{[1]}$. Consequently, postoperative calcium regulation therapy is the most important in perioperative period. This study summarizes comparatively mature postoperative calcium regulation schemes from two centers in recent years, and statistically analyzes the clinical data of patients and the risk factors related to calcium regulation in perioperative period.

\section{Methods}

\section{Materials}

Clinical data of 136 diagnosed patients of secondary hyperparathyroidism, from Jan 2017 to Dec 2019 , who received long treatment of dialysis for chronic renal failure in uremic stage

Inclusion criteria: 1. Secondary hyperparathyroidism in uremic stage of chronic renal failure diagnosed before operation; 2 . Compliance with operation indications: 1) patients with symptoms; 2) abnormal calcium and phosphorus metabolism due to ineffective medicine treatment; 3 ) preoperative PTH value $>800 \mathrm{pg} / \mathrm{ml}$;) At least one parathyroid gland was $>1 \mathrm{~cm}$ in the diameter and the blood flow was abundant; which was consistent with anyone of the above items. 3 . There was no serious complication in the perioperative period;

Exclusion criteria: 1 . Severe cardiopulmonary cerebral dysfunction, which resists general anesthesia and surgery; 2 . Severe liver dysfunction, coagulation dysfunction;

The operation was performed by senior doctors; the patients and their families signed the informed consent related to the operation;

\section{Surgical Preparation}

All indexes were improved after admission, such as blood routine, blood coagulation, thyroid function, liver and kidney function, PTH, ion series, etc; Physical examination, such as thyroid and parathyroid ultrasound, neck computed tomography(CT) scan, parathyroid MIBI and electronic laryngoscope, etc; Heparin free dialysis was performed one day before operation;

The catheterization of the subclavian vein was performed. The parathyroid gland grafted during the autotransplantation was well organized and appeared no obvious hyperplastic granules, weighing about $30-60 \mathrm{mg}$. It had been cut into pieces with a diameter of about $1 \mathrm{~mm}$, and implanted into the quadriceps femoris of the left thigh of the patient. The cervical cavity was retained for drainage.

\section{Postoperation}


$1 \mathrm{~g}$ of calcium gluconate injection was slowly injected before the recovery from anesthesia, and the dose was determined according to the recovery of patients' spontaneous respiration and the muscle strength of skeletal muscle. After recovery from anesthesia, calcium gluconate injection was pumped into the deep vein immediately, and the initial speed was set as 1.0-1.5 g/h. After the operation, the observation indexes were measured according to the time axis, i.e. the operative day and the $1 \mathrm{st}$, the $2 \mathrm{nd}$, the $3 \mathrm{rd}$, the 5 th, the 7 th, the 10 th and the 15 th after operation, the time node of calcium regulation was that the PTH value rose to the normal range and the patients had no discomfort symptoms; the calcium gluconate concentration and pump speed were adjusted according to the results of relevant indicators. The patients were monitored for discomfort symptoms during the process, such as: numbness and convulsion of hands and feet, headache, insomnia, acupuncture sensation of lips, palpitation and agitation, etc. The drainage was removed on the second day after operation.

The arrangement of postoperative dialysis was in accordance with the routine dialysis before operation, and heparin free dialysis was recommended for the first time.

\section{Observation Index}

Patients were divided into the observation group ( $\leq 7$ days) and the control group ( $>7$ days) according to postoperative calcium regulation time; Each index was compared between the two groups, including: age, gender, preoperative dialysis time, dialysis mode, complications, preoperative oral calcium, preoperative calcium value, preoperative HB value ,PTH value, ALP value, operation methods, etc;

\section{Statistical Methods}

Collated data were analyzed statistically on the software SPSS 21.0. All the measurement data are expressed by mean \pm standard deviation ( \pm s);All the comparisons between the two groups are tested by independent sample t; All the counting data are showed by Frequency and Percentage, and their comparability adopts $\chi^{2}$ test; Logistic regression is used to carry out Single factor and Multi-factor analysis on the relevant factors, and the standard level a is 0.05 , the difference was statistically significant when $p<0.05$.

\section{Results}

\section{Single factor analysis of postoperative calcium regulation by general data}

136 patients were included in this study, containing 60 males and 76 females, 30 males and 38 females in the observation group, 30 males and 38 females in the control group, there was no significant statistical difference between the two groups $\left(X^{2}=0.392, P=0.332\right)$; The mean age was (49.06 \pm 12.259$)$ years, the mean age of the observation group was (54.01 \pm 9.215$)$ years, and that of the control group was (44.10 \pm 12.964$)$ years, the difference between the two groups was statistically significant $(P<0.01)$; The duration of preoperative dialysis was $(5.05 \pm 2.855)$ years in the observation group and $(6.99 \pm$ 3.436) years in the control group, the difference between the two groups was statistically significant $(P<0.01)$; The dialysis methods include peritoneal dialysis and hemodialysis, 29 cases in the observation group in the peritoneal dialysis, 39 cases in the hemodialysis, 31 cases in the control group in the peritoneal dialysis and 37 cases in the hemodialysis, the difference between two groups was no statistically significant $(P=0.467)$; With or without complication, there was no significant difference between the two groups $(P=0.467)$. Preoperative oral calcium: 47 cases in the observation group took calcium before operation, 21 cases did not take calcium, 24 cases in the control group took calcium, 44 cases did not take calcium, the difference between the two groups was statistically significant $\left(X^{2}=9.941, P=0.002\right)$; Operation mode: in the observation group, 28 cases underwent SPTX, 19 cases underwent TPTX, 21 cases underwent TPTX-AT, and that is respectively 33 cases, 19 cases, 16 cases in the control group, the difference between the two groups was statistically significant $(P=0.026)$; The mean time of postoperative calcium regulation was $(7.67 \pm 2.823)$ days, which's the reason to divide into two groups as "7 days". Table 1 for details. 
Summary of general information

\begin{tabular}{|c|c|c|c|c|c|c|c|c|c|c|c|c|c|}
\hline & \multicolumn{2}{|l|}{ Sex } & \multirow[t]{2}{*}{$\begin{array}{l}\text { age } \\
\text { (years) }\end{array}$} & \multicolumn{2}{|c|}{$\begin{array}{l}\text { preoperative } \\
\text { calcium } \\
\text { intake (n) }\end{array}$} & \multirow[t]{2}{*}{$\begin{array}{l}\text { preoperative } \\
\text { dialysis } \\
\text { time (years) }\end{array}$} & \multicolumn{2}{|c|}{ preoperative dialysis mode } & \multicolumn{3}{|c|}{ operation mode } & \multicolumn{2}{|c|}{$\begin{array}{l}\text { complications } \\
\text { (n) }\end{array}$} \\
\hline & $\begin{array}{l}\text { Male } \\
\text { (n) }\end{array}$ & $\begin{array}{l}\text { Female } \\
\text { (n) }\end{array}$ & & Yes & No & & $\begin{array}{l}\text { Hemodialysis } \\
\text { (n) }\end{array}$ & $\begin{array}{l}\text { peritoneal } \\
\text { dialysis } \\
\text { (n) }\end{array}$ & SPTX(n) & $\begin{array}{l}\text { tPTX } \\
\text { (n) }\end{array}$ & $\begin{array}{l}\text { TPTX- } \\
\text { AT } \\
\text { (n) }\end{array}$ & Yes & No \\
\hline $\begin{array}{l}\text { Observation } \\
\text { group }\end{array}$ & 30 & 38 & $\begin{array}{l}54.01 \\
\pm \\
9.215\end{array}$ & 47 & 21 & $5.05 \pm 2.855$ & 39 & 29 & 28 & 19 & 21 & 39 & 29 \\
\hline $\begin{array}{l}\text { Control } \\
\text { group }\end{array}$ & 30 & 38 & $\begin{array}{l}44.10 \\
\pm \\
12.964\end{array}$ & 24 & 44 & $6.99 \pm 3.436$ & 31 & 37 & 33 & 19 & 16 & 37 & 31 \\
\hline$\chi^{2} / P$ & \multicolumn{2}{|c|}{$\begin{array}{l}\chi^{2}=0.392, P= \\
0.332\end{array}$} & $P \llbracket 0.01$ & \multicolumn{2}{|c|}{$\begin{array}{l}\chi^{2}=9.941 \\
P=0.002\end{array}$} & $P \rrbracket 0.01$ & \multicolumn{2}{|l|}{$P=0.467$} & \multicolumn{3}{|l|}{$P=0.026$} & \multicolumn{2}{|c|}{$P=0.467$} \\
\hline
\end{tabular}

\section{Operation}

All the 136 operations were performed by senior doctors, and none of patients were found breath holding, dysphagia, low pitch, numbness or convulsion, hoarseness, etc. The symptoms of myalgia, osteodynia, pruritus, insomnia, dysphoria and epilepsy were alleviated obviously, and 136 patients were discharged smoothly.

\section{Single-factor analysis and Multivariate analysis of the influence of preoperative indexes on postoperative calcium regulation}

The mean time of postoperative calcium regulation was (5.25 \pm 1.164$)$ days in the observation group and (10.09 \pm 1.682$)$ days in the control group, there was a significant difference between the two groups ( $t=53.529 ; P<0.001)$; The preoperative HB value of the observation group (119.324 \pm 22.59$) \mathrm{g} / \mathrm{l}$, the control group $(111.84 \pm 20.29) \mathrm{g} / \mathrm{l}$, and there was no significant difference between the two groups $(t=1.972 ; P=0.053)$; The preoperative calcium value of the observation group was $(2.55 \pm 0.33) \mathrm{mmol} / \mathrm{L}$, the control group was $(2.32 \pm 0.22) \mathrm{mmol} / \mathrm{L}$, the difference between the two groups was statistically significant $(t=4.795 ; P<0.001)$; The preoperative PTH value of the observation group was $(1449.30 \pm 711.70) \mathrm{ng} / \mathrm{L}$, the control group was $(2422.84 \pm 1045.34)) \mathrm{ng} / \mathrm{L}$, the difference between the two groups was statistically significant $(t=6.327 ; P<0.001)$; The preoperative ALP value of the observation group was $(243.43 \pm 257.73) \mathrm{U} / \mathrm{L}$, the control group was $(496.26 \pm 518.84) \mathrm{U} / \mathrm{L}$, the difference between the two groups was statistically significant $(\mathrm{t}=3.527 ; \mathrm{P}=0.001)$, as shown in Table 2.

The results of multivariate analysis showed that age, preoperative calcium value, preoperative PTH value and preoperative ALP value were the independent factors influencing postoperative calcium regulation,as shown in Table 3.

Table 2

Single factor analysis of the influence of preoperative indexes on postoperative calcium regulation

\begin{tabular}{|lllll|}
\hline & $\begin{array}{l}\text { calcium pumping time } \\
\text { (days) }\end{array}$ & $\begin{array}{l}\text { Preoperative HB } \\
\text { value } \\
(\mathrm{g} / \mathrm{l})\end{array}$ & $\begin{array}{l}\text { preoperative } \\
\text { calcium } \\
(\mathrm{mmol} / \mathrm{L})\end{array}$ & $\begin{array}{l}\text { preoperative PTH } \\
(\mathrm{ng} / \mathrm{L})\end{array}$ \\
\hline $\begin{array}{l}\text { Observation } \\
\text { group }\end{array}$ & $5.25 \pm 1.164$ & $119.324 \pm 22.59$ & $2.55 \pm 0.33$ & $1449.30 \pm 711.70$ \\
\hline Control group & $10.09 \pm 1.682$ & $111.84 \pm 20.29$ & $2.32 \pm 0.22$ & $2422.84 \pm 1045.34$ \\
\hline $\begin{array}{l}\mathrm{A} / \mathrm{P} \text { value } \\
\mathrm{t}=53.529 ;\end{array}$ & $\mathrm{P} \otimes 0.001$ & $\begin{array}{l}\mathrm{t}=1.972 ; \\
\mathrm{P}=0.053\end{array}$ & $\begin{array}{l}\mathrm{t}=4.795 ; \\
\mathrm{P} \otimes 0.001\end{array}$ & $\begin{array}{l}\mathrm{t}=6.327 ; \\
\mathrm{P} \otimes 0.001\end{array}$ \\
\hline
\end{tabular}

\begin{tabular}{|c|c|c|}
\hline & $\mathrm{C}^{2}$ & $\mathrm{P}$ value \\
\hline Operation method & 9.042 & 0.618 \\
\hline Gender & 7.989 & 0.714 \\
\hline Preoperative dialysis time & 14.316 & 0.216 \\
\hline Preoperative dialysis & 4.572 & 0.950 \\
\hline Complications & 6.179 & 0.861 \\
\hline Preoperative PTH value & 32.899 & 0.001 \\
\hline Preoperative calcium value & 31.202 & 0.001 \\
\hline Preoperative HB value & 15.507 & 0.160 \\
\hline Preoperative ALP value & 11.408 & 0.010 \\
\hline Age & 27.084 & 0.004 \\
\hline Preoperative calcium value & 34.045 & 0.000 \\
\hline
\end{tabular}


The two groups was statistically significant $(\mathrm{P}<0.05)$

Table 3

Multivariate analysis of the influence of preoperative indexes on postoperative calcium regulation

\section{Discussion}

With the prolongation of dialysis (peritoneal dialysis or hemodialysis) treatment time for patients with chronic renal failure in uremic stage, the risk of abnormal mineral bone metabolism in chronic kidney disease(CKD-MBD) increased. The Dialysis Outcomes and Practice Pattern Study(DOPPS) research shows that the incidence rate is $40-50 \%{ }^{[2]}$. The secondary changes of parathyroid function are caused by the abnormal metabolism of calcium and phosphorus, the lack of vitamin D and the decrease of its receptor sensitivity, and the rise of the balance point of calcium regulation in the body, then bone pain, myalgia, skeletal deformity, atherosclerotic changes of cardiovascular system and neuropathy occurred ${ }^{[3]}$. As a safe and effective therapy, surgical treatment has been widely used in clinical practice, but serious postoperative complications have become the difficulty of perioperative treatment, especially hypocalcemia, which has a probability of about $97 \%$. Severe hypocalcemia can be manifested as: respiratory distress, numbness and convulsion of hands and feet, insomnia, headache, acupuncture sensation of lips, palpitation and agitation, fidgety, induced epilepsy, malignant arrhythmia, etc. Intravenous pumping of Portugal Calcium Gluconate is the main treatment ${ }^{[4]}$. The purpose of this study is to come up with the safe and effective postoperative calcium regulation schemes, and to find that age, preoperative dialysis time, operation method, preoperative calcium value, PTH value, ALP value are closely related to them.

The results of this study show that age is an independent risk factor for postoperative calcium regulation, that is, the younger the patients are, the longer the time of postoperative calcium pumping is. The reason is that young patients need more calcium for their own growth. At the same time, the systemic calcium loss is caused by repeated dialysis treatment, so the perioperative calcium demand is greater. However, some scholars ${ }^{[5]}$ have come to the opposite conclusion. They believe that the absorption of calcium and calcitriol and other drugs in the gastrointestinal tract of the elder patients is more serious, and hypocalcemia is more likely to occur; Therefore, the correlation between age and hypocalcemia needs more data to be confirmed. At the same time, bone density detection and bone biopsy can be used as objective means to evaluate the whole body bone content, but because of their technical requirements and patients' wishes, it can not be widely used in clinical.

As the most important detection index in perioperative period, blood calcium can directly reflect the quality of operation, and is closely related to the occurrence of postoperative symptoms ${ }^{[6]}$. The key to avoid severe symptoms, especially convulsion caused by hypocalcemia, is to maintain the stability of blood calcium after operation. A rigorous and safe postoperative calcium regulation scheme is directly related to the prognosis of patients. This study confirms that preoperative calcemia value is an independent risk factor of postoperative calcium regulation time, that is, preoperative calcium value is negatively related to postoperative hypocalcemia; Therefore, the blood calcium adjustment should run through the whole treatment process, even before the operation. Routine application of oral calcium before surgery can reduce the incidence of postoperative hypocalcemia and shorten the postoperative calcium regulation time. At the same time, the results of this study confirm that the appropriate use of oral calcium before operation can alleviate bone hunger in varying degrees, so as to shorten the postoperative calcium regulation time, which can be used as a routine treatment in the perioperative period.

Preoperative PTH value reflects parathyroid function. In patients with chronic renal failure in uremic stage undergoing dialysis treatment for a long time, the release of PTH in blood is stimulated by the whole body's osteolysis reflex, so as to promote bone absorption. After surgical removal of the pathological parathyroid gland, PTH value drops sharply, bone resorption is impaired, and then serious hypocalcemia occurs. Some scholars ${ }^{[7]}$ have confirmed that when the preoperative PTH value is more than $1750 \mathrm{ng} / \mathrm{L}$, the probability of occurrence of hypocalcemia increased 6.8 times. This study shows that when parathyroid hormone is greater than $1449.30 \mathrm{ng} / \mathrm{L}$, it is necessary to strictly implement calcium regulation program to avoid hypocalcemia caused by premature suspension or reduction of calcium pumping. This study also confirms that preoperative PTH value was positively correlated with the postoperative calcium regulation time, that is, the higher preoperative PTH value, the more postoperative calcium demand, and the longer calcium regulation time.

Serum ALP is a key enzyme to promote bone calcification, which will increase in varying degrees for liver disease and bone marrow disease. Serum ALP value in the patients with chronic renal failure in uremic stage can reflect the severity of renal osteodystrophy, that is, the severity of bone hunger syndrome after operation. Kidney Disease: Improving Global Outcomes (KDIGO) suggests that Serum ALP value in blood can be used to evaluate the severity of CKD$\mathrm{MBD}^{[1]}$. Ho LY and other scholars ${ }^{[8]}{ }^{[9]}$ have confirmed that the higher the preoperative ALP value is, the greater the probability of hypocalcemia is after operation, and the more calcium dose needs to be supplemented. This study combines with preoperative ALP value to determine the degree of bone hunger in the whole body and indirectly guide the time of postoperative calcium regulation, especially the preoperative ALP value is greater than $243.43 \mathrm{U} / \mathrm{L}$, that is, the higher the preoperative ALP value is, the greater the degree of bone hunger is, the longer the time of calcium supplementation is, which is an independent risk factor affecting postoperative calcium regulation.

Hypocalcemia is the most serious complication in the perioperative period of surgical treatment of secondary hyperparathyroidism. The measurement and evaluation of preoperative related indicators can better estimate the prognosis, so as to develop a safe and effective calcium regulation therapy. However, the disease situation of patients undergoing dialysis treatment is more complex, and the influencing factors are diverse. The study of double centers and a small sample can not fully cover it. Therefore, more in-depth research still needs big data, especially the widely popularized operation methods and quantitative calcium regulation, etc.

\section{Conclusions}


Accurate and detailed postoperative calcium regulation scheme in perioperative period is very important for the postoperative recovery of patients with secondary hyperparathyroidism. The calcium regulation scheme recorded in this study has been proved to be simple, safe and easy in clinical application. Meanwhile, the relevant factors affecting the postoperative calcium regulation have been detailed analyzed and the timely intervention could be taken to reduce the occurrence of serious complications, especially hypocalcemia, which could lead to serious consequences.

\section{Abbreviations}

secondary hyperparathyroidism $\triangle$ SHPT囚

Subtotal parathyroidectomy (SPTX)

Total parathyroidectomy (tPTX)

Total Paratyroidectomy with autotransplatation (TPTX-AT)

Parathyroid Hormone (PTH)

Alkaline phosphatase (ALP)

Hemoglobin (HB)

computed tomography (CT)

mineral bone metabolism in chronic kidney disease (CKD-MBD)

The Dialysis Outcomes and Practice Pattern Study (DOPPS)

Kidney Disease: Improving Global Outcomes (KDIGO)

\section{Declarations}

\section{Ethics approval and consent to participate}

All procedures followed were in accordance with the ethical standards of the responsible committee on human experimentation (institutional and national) and with the Helsinki Declaration of 1964 and later versions. The operation and the related treatment plans approved by the clinical practice guideline[1].The study has been granted an exemption from the Ethics Committee of the Second Affiliated Hospital of Dalian Medical University and Jinzhou Central Hospital Ethics Committee; Informed consent was obtained from all individual participants included in the study.

[1] Kidney Disease:Improving Global Outcomes(KDIGO), CDK-MBD work Group. KDIGO 2017 clinical practice guideline update for the diagnosis evaluation, prevention, and the treatment of chronic kidney disease-mineral and bone disorder(CDK-MBD)[J]. Kidney Int Suppl, 2017, 7(1):1-59.

\section{Consent for publication}

All authors agreed with the content and all gave explicit consent for publication.

\section{Availability of data and material}

All data generated or analyzed during this study are included in this published article and its supplementary information files.

\section{Competing interests}

There is no conflict of interest in this research.

Funding Not applicable

\section{Authors' contributions}

All authors contributed to the study conception and design. Material preparation, data collection and analysis were performed by JIA D, YF W, BZ, JIN D, and YM. Dr. XSZ summarized the overall treatment plan, designed the experimental ideas, checked the experimental data, calculated the statistical data. The first draft was written by WBZ and the previous versions of the manuscript were commented by all the other authors. The final manuscript was read and approved by all the authors.

\section{Acknowledgments}

Thanks to all the people, JIA D, YF W, BZ, JIN D, and YM, who participated in the data collection, collation and statistics of the research; Thanks to Dr. XSZ for his constructive revision of the research and his valuable comments, and thanks to the relevant departments of the hospital for their strong support for the research, such as general surgery, anesthesiology, imaging, laboratory, etc. Thank you very much. 


\section{References}

[1]Isakova T, Nickolas TL, Denburg M, et al. KCOQI US commentary on the 2017 KDIGO clinical practice guideline update for the diagnosis, evaluation, prevention, and treatment of chronic kidney disease-mineral and bone disorder(CKD-MBD)[J], Am J kidney Dis, 2017, 70(6):737-751.

[2]komaba H, Taniguchi M, Wada A, et al. Parathyriodectomy and survival among Japnese hemodialysis patients with secondary hyperparathyroidism [J]. Kidney Int,2015,88(2):350-359.

[3]Kopple JD. National kidney foundation K/KOQI clinical practice guidelines for nutrition in renal failure[J]. Am J Kidney Dis, 2001,37(s2):66-70.

[4]Kidney Disease:Improving Global Outcomes(KDIGO),CDK-MBD work Group. KDIGO 2017 clinical practice guideline update for the diagnosis evaluation, prevention, and the treatment of chronic kidney disease-mineral and bone disorder(CDK-MBD)[J]. Kidney Int Suppl, 2017, 7(1):1-59.

[5]Yang M, Zhang L, Huang L,et al. Factors predictive of critical value of hypocalcemia after total parathyroidectomy without autotransplantation in patients with secondary hyperparathyroidism[J]. Transplant Proc, 2009, 41(9):3642-3626.

[6]Yang M, Zhang L, Huang L, et al. Factors predictive of critical value of hypocalcemia after total parathyroidectomy without autotransplantation in patients with secondary hyperparathyroidism[J]. Ren Fail, 2016,38(8):114-119.

[7]Thyroid Surgeons Committee of Surgeons Branch of Chinese Medical Association, Professional Committee on thyroid Disease of Chinese Society of Research Hospitals. Expert consensus on clinical practice of hyperparathyoidism secondary to chronic renal failure[J], Chinese Journal of Practical Surgery, 2016,36(5):481-486

[8]Ho LY, Wong PN, Sin HK, et al. Risk factors and clinical course of hungry bone syndrome after total parathyroidectomy in dialysis patients with secondary hyperparathyroidism[J]. BMC Nephrol, 2017,18:12.

[9]Heng, Geng Xiaoping, Chen Jiangming,et al. Related factors analysis for persistent severe hypocalcemia after parathyroidectomy in secondary hyperparathyroidism patients[J]. Chinese Journal of Endocrinology and Metabolism,2018,34(1):57-60.

\section{Supplementary Files}

This is a list of supplementary files associated with this preprint. Click to download.

- source.xlsx 